\title{
Design and Evaluation of the Transparent Liquid Leakage Sensing Device
}

\author{
Masaki Fujikawa and Kenta Miyazaki
}

\begin{abstract}
Nowadays, most manufacturers and offices handle and use a large amount of liquid (water, seasonings, oil, etc.) every day to produce products and provide services to their customers. In general, liquid sensing devices are installed outside of a tank to detect liquid leakage more quickly. Authors considered that the transparent liquid sensor has potential needs from customers because of the existence of several types of transparent tanks, but currently, there are no sensors with transparency. In this paper, the 2-dimensional flexible transparent liquid sensing device is proposed. This device was successfully created with high light-transmission rate $(84.9 \%)$, and could detect familiar liquids (e.g., tap water, distillated water, weak acid/alkali liquid, and strong acid/alkali liquid) with the exception of low electrical conductivity liquids (e.g., oil and alcohol). This sensing unit can be provided to the market at an affordable price by using printing technologies.
\end{abstract}

Index Terms-Flexible, liquid leakage sensing device, transparent, two dimensional sensing.

\section{INTRODUCTION}

\section{A. Necessity of Liquid Leakage Sensing}

In daily operation at factories and business places certain kinds of liquids are used in manufacturing products and for provision of services to customers. For example in the semiconductor factories, deionized water is used for rinsing of wafers; in food factories, soy sauce and vinegar are used for cooking; and in offices, kerosene or gas oil is used for water heaters and/or for generator set. Such liquids are stored in tanks and the required quantity is taken from the tank so that production or provision of services can be made in a stable manner.

Such liquids stored in the factories or business places are an asset to running the business but may be a substance that is hazardous to human health and the natural/living environment. Because of this, factories and business places use tanks that seldom leak and install sensing devices that detect leakage of the liquid quickly to prevent expansion of loss of the asset and minimize any adverse impact.

\section{B. Conventional Sensing Device}

Explanation of the conventional sensing devices for liquid leakage is given in this subsection. Principles of leakage detection can be classified into two (see Table I) and the shape of the devices can be classified into four (see Fig. 2).

\footnotetext{
Manuscript received September 19, 2014; revised April 24, 2015.

Masaki Fujikawa is with the ALSOK Security Science Institute, Ishijima 2-14, Koto-ku, Tokyo 135-0014, Japan (e-mail: fujikawa-masaki@alsok.co.jp).

Kenta Miyazaki is with the Nagaoka University of Technology, Nagaoka city, Niigata Prefecture 940-2188, Japan.
}

\section{1) Principle of detection}

The electrical type utilizes change in electrical behavior of the sensing device due to contact with the liquid, which is suitable for detection of liquid leakage with high electrical conductivity. On the other hand, the optical type utilizes changes in optical behavior of the sensing device due to contact with the liquid, which is suitable for detection of the liquid with low electrical conductivity (oil etc.) and high conductivity. (Because this type does not utilize electrical behavior for the liquid, it is used for detection of oil leakage for explosion proof consideration.)

\section{2) Geometry of the sensing device}

The sensing device in tablet shape [1]-[7] detects liquid leakage zero-dimensionally. Because it is a point detection sensor, detection of leakage is easier when installed in the center of the drip pan, which is sunken at the center and placed underneath the tank or piping.

TABLE I: PRINCIPLES OF LIQUID LEAKAGE DETECTION

\begin{tabular}{|c|c|}
\hline Type & Characteristics \\
\hline Electrical Type & $\begin{array}{l}\text { This type utilizes the short-circuit phenomenon of } \\
\text { the sensing device when it makes contact with the } \\
\text { liquid and can be divided to the type that detects } \\
\text { change in resistance [3], [4], [8], [9], [11], [12] and } \\
\text { the type that monitors change in voltage transmitted } \\
\text { to the sensing device [5], [10]. }\end{array}$ \\
\hline Optical Type & $\begin{array}{l}\text { This type utilizes the phenomenon that the photo } \\
\text { detector cannot receive light transmitted from the } \\
\text { light emitter of the sensing device when it makes } \\
\text { contact with the liquid [1], [2], [6], [7]. }\end{array}$ \\
\hline \multicolumn{2}{|c|}{ TABLE II: SHAPE OF EACH SENSING DEVICES } \\
\hline Type & Characteristics \\
\hline $\begin{array}{l}\text { Tablet Shape } \\
\text { (Point detection } \\
\text { type) }\end{array}$ & $\begin{array}{l}\text { The sensing device has a tablet shape (diameter of } \\
\text { about } 4 \mathrm{~cm} \text { and thickness about } 1.5 \mathrm{~cm} \text { ) and detects } \\
\text { liquid leakage zero dimensionally. Principle of } \\
\text { detection is either electrical or optical. }\end{array}$ \\
\hline $\begin{array}{l}\text { String or Belt } \\
\text { Shape (Line } \\
\text { detection type) }\end{array}$ & $\begin{array}{l}\text { The sensing device has a string configuration } \\
\text { (diameter of about } 3.5-5 \mathrm{~mm} \text { ) or belt configuration } \\
\text { (width of about } 5-8 \mathrm{~mm} \text {, thickness of about } 1 \mathrm{~mm} \text { ) } \\
\text { and detects liquid leakage one-dimensionally. The } \\
\text { principle of detection is electrical. }\end{array}$ \\
\hline $\begin{array}{l}\text { Plate Shape (Point } \\
\text { and Plane } \\
\text { detection type) }\end{array}$ & $\begin{array}{l}\text { The sensing device has a plate shape (Width of } 8.5 \\
\mathrm{~cm} \text { and length of } 12 \mathrm{~cm} \text { ) and detects liquid leakage } \\
\text { zero-dimensionally or two-dimensionally. The } \\
\text { principle of detection is electrical. }\end{array}$ \\
\hline $\begin{array}{c}\text { Sheet Shape } \\
\text { (Plane detection } \\
\text { type) }\end{array}$ & $\begin{array}{l}\text { The sensing device in the sheet shape detects liquid } \\
\text { leakage two-dimensionally. The principle of } \\
\text { detection is electrical. }\end{array}$ \\
\hline
\end{tabular}

The sensing devices in cord or belt shape [8]-[10] detect liquid leakage one-dimensionally. Because it is linear 
detection sensor and is flexible, it can be used to detect leakage when wrapped around the tank and piping in spiral or placed in zigzag pattern on the floor surface underneath the tank or piping.

The sensing device in the plate shape [11] detects liquid leakage zero-dimensionally or two-dimensionally with the sensor in a cord or belt shape (with very small diameter) arranged in a zigzag pattern on the plastic plate. Because it is a point or planar detection sensor, it can be installed like the tablet shaped point sensing device or directly underneath the tank to detect liquid leakage.

The sensing device in the sheet shape [12] detects liquid leakage two-dimensionally. Because it is a planar detection sensor and is flexible, it can be used to detect leakage by bonding to the tank or piping surface or placing on the floor underneath the tank and piping.

\section{Potential Needs for Transparent Sensing Device}

The conventional liquid leakage sensor explained earlier is not transparent. This will be because no request was made to the manufacturers of sensors stating that the liquid leakage sensor must be (or preferably be) transparent by the factories or business places, or even when such requests were made, the numbers may be very few and were neglected for realization as a product.

TABLE III: EXAMPLES OF POTENTIAL CUSTOMERS

\begin{tabular}{cl}
\hline $\begin{array}{c}\text { Factory/Business } \\
\text { Place }\end{array}$ & \multicolumn{1}{c}{ Example of Installed Sensing Devices } \\
\hline $\begin{array}{c}\text { Tropical fish store } \\
\text { / fish store / } \\
\text { restaurant / fish } \\
\text { culture facility / } \\
\text { aquarium }\end{array}$ & $\begin{array}{l}\text { Installation of a transparent liquid leakage sensing } \\
\text { device at the side or bottom of the transparent } \\
\text { showcase, glass tank, and restaurant's fish tank filled } \\
\text { with seawater or fresh water. }\end{array}$ \\
\hline $\begin{array}{c}\text { Factory / business } \\
\text { place receiving } \\
\text { visitors }\end{array}$ & $\begin{array}{l}\text { Installation of a transparent liquid leakage sensing } \\
\text { device at the side or bottom of the transparent tanks } \\
\text { used for demonstration to visitors which is filled } \\
\text { with beverage or liquid with a culture solution. }\end{array}$ \\
\hline \hline
\end{tabular}

The authors consider that there are potential needs for transparent liquid leakage sensors. It is because the use of non-transparent liquid leakage sensing devices when installed on the transparent tank, showcase, or piping will be unnatural to those looking to find what is inside, will obstruct the view inside the tank, or will impair the intended design of the showcase or restaurant's fish tank, as a transparent tank, showcase, and piping are installed for display or demonstration in the factory or business place shown in Table III.

Two-dimensional liquid leakage is desirable so that leakage can be detected quickly. As shown in Table II, sensing devices other than the sheet shape must use a drip pan or zigzag arrangement of the device to make two-dimensional detection possible for quick detection of leakage. Additionally, two-dimensional sensing devices should preferably have flexibility like sheet-shaped sensing devices. This will make the device have the advantage of the sheet-shaped sensing device.

Based on the above considerations, the authors decided to develop a sheet-shaped sensing device that is transparent and can detect liquid leakage two-dimensionally.

\section{PREMISES AND CRITERIA}

In this section, the premises used and the criteria for performance evaluation of the prototype sensing device in this report are explained.

\section{A. Premises}

1) As far as the authors have investigated, there is no appropriate evaluation method for a transparent sensing device of liquid because such device has never been developed. Accordingly, evaluation of the prototype sensing device developed is made using the indices of visible transmittance, two-dimensional sensing capability, and flexibility that the device must be equipped with.

2) Although strict evaluation of the performance of the sensing device is required before such sensing device is commercially sold, the prototype device produced has not reached the marketing phase yet. So the authors evaluated leakage detection performance simply in the indoor environment where no condensation on the sensing device occurs where abrupt temperature change is not present (temperature 18-20 degrees $\mathrm{C}$ and $\mathrm{RH} 40 \%$ to $50 \%$ ).

\section{B. Criterion 1 (Visible Transmittance)}

The visible transmittance is a value expressed in zero to 100 percent which represents transparency of the substance. The following index for development of the transparent sensing device is established.

Visible transmittance of the sensing device should be $70 \%$ or higher.

The reason why $70 \%$ is used as the criterion is because the visible transmittance of the PC screen protection film which should be sufficiently high is generally $70 \%$ or higher [13] and visible transmittance of the windshield of a car that directly relates to safety is also required to be $70 \%$ or higher [14], and the authors consider that 70 percent is appropriate for this application.

\section{Criterion 2 (Two-dimensional Sensing)}

The objective of the authors is development of the sensing device that can detect liquid two-dimensionally. So the following criterion is established.

The sensing device formed in sheet shape is placed on the horizontal plane. Then a small quantity of liquid is dropped at any point as a center. Verify that the electrical or optical behavior of the device changes meaningfully and the device functions as the sensing device.

As far as the authors have investigated, no standard or guideline is available to evaluate performance of two-dimensional liquid leakage detection. On the other hand, manufacturers of the string or belt shape sensing devices evaluate performance of their sensing devices by dropping liquid droplets directly on the device as stated above [15]. Considering these, the authors decided to evaluate the performance by the above criterion. 


\section{Criterion 3 (Flexibility)}

The objective of the authors is development of the sensing device in a sheet shape. It is contemplated that the device will be used on the three-dimensional object like a tank or piping, and the device shall not be damaged due to bending during application and reapplication. So the following criterion is established.

After the device is applied to the vertical surface using a double-sided adhesive tape, it is peeled off by pulling the end of the device in the direction of 90 degrees. It should be verified that the device is not damaged after it is peeled off.

The standard and guideline used to evaluate durability of the device rather than flexibility are available to the knowledge of the authors. For example, such standard or guideline is applied to the wiring that should not necessarily be transparent on which the reciprocating motion of the moving section is repeated in a bent condition in a small radius of curvature like a Flexible Printed Circuit (FPC). Since the device developed by the authors will not subject to continuous reciprocating motion like FPC, flexibility of the device is evaluated by the criterion defined above. The test method explained above is used as the testing method of adhesive strength of the adhesive tape [16]. Because it is considered that the device is applied using a transparent glue, the above criterion will be appropriate.

\section{Design AND PRototyping}

In this section, design objectives and detail of the specific design and prototyping of the device are explained.

\section{A. Objective}

The authors decided to develop the transparent sensing device satisfying the three criteria by arranging hardly visible very thin conductive lines on the transparent two-dimensional plane as inspired by two-dimensional arrangement of the string or belt type sensing device in a single stroke zigzag pattern. The principle of detection used is electrical as in the case of a string or belt type sensing device and to facilitate verification of effectiveness of the prototype device, a decrease of electrical resistance due to a short-circuit in the conductive lines by the liquid, which is a common behavior, is used.

The authors decided to use a manufacturing technique of the conductive transparent film commonly used as the touch panel for tablet PCs as the prototype. This technique relates to printing of the conductive lines using conductive particles on the transparent PET sheet, which surpasses the conventional transparent conductive film using Indium Tin Oxide (ITO) in the following points.

1) Flexibility and low electrical resistivity: Because ITO is a hard material, conductive lines will fail due to bending of the film, but conductive particles result in flexible material that does not easily fail by bending [17]. Surface resistance of $0.1 \Omega / \mathrm{sq}$ that cannot be realized by ITO can be achieved [18].

2) Mass productivity: Production of ITO film requires large deposition equipment and includes exposure, development, etching, and cleaning processes, but such processes are not required for the transfer process using conductive particles. So, this method is suitable for mass production [17].

3) Printing performance: This process also allows transfer of any type of patterns that cannot be produced by ITO [17], and a pattern created by CAD or draw software can be used as the artwork. This method makes printing on glass or polycarbonate sheet possible [17].

\section{B. Design 1 (Configuration of Conductive Lines)}

First, configuration of the conductive lines printed on the transparent two-dimensional sheet is discussed. The visible transmittance of the transparent conductive film will increase with a decrease of the conductive line width. At present it is possible to print a conductive line in $14 \mu \mathrm{m}( \pm 1 \mu \mathrm{m})$ width, but because conductive particles such as silver powder is used in printing, it is possible that the printed pattern may become intermittent (i.e., electrical conductivity of the line is lost due to interruption of the printed pattern). When a single conductive line is printed in a single line two dimensionally on the two-dimensional plane according to the usual pattern of placing the string or belt shaped sensing devices on the plane, low yield of the products is likely due to the defect that lacks conductivity. To reduce interruption of the printed conductive lines, width of the line may be increased but it will impair visible transmittance due to obstruction of visible lights, and easy identification of the presence of the conductive line is a concern.

So the authors have decided to use conductive lines in mesh pattern inspired by the mesh woven with thin strings. It is expected that this will reduce amount of obstructed visible light and will keep identification of the conductive lines difficult.

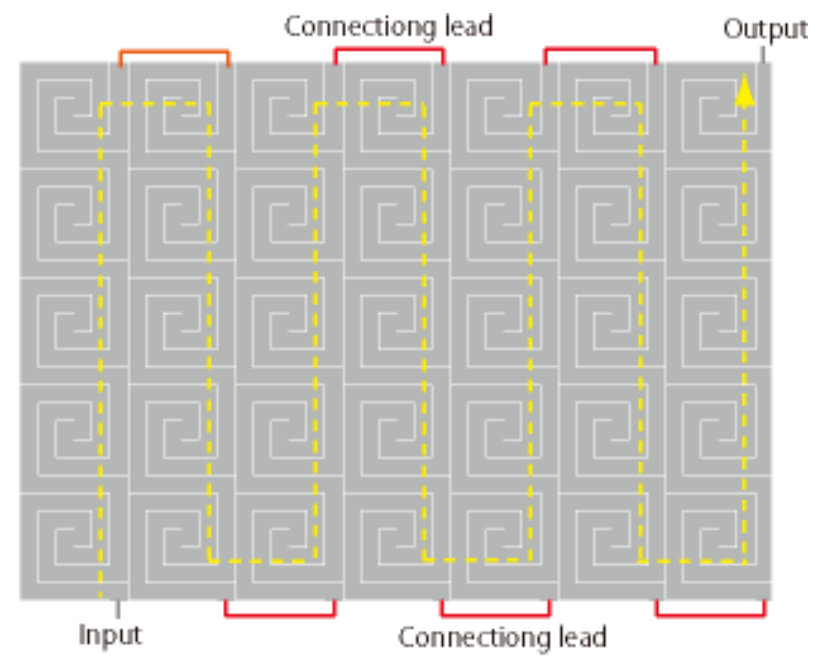

Fig. 1. Arrangement image of conductive lines

\section{Design 2 (Arrangement of Conductive Lines)}

Next, the layout pattern of the conductive lines printed on the transparent two-dimensional sheet is discussed.

The authors contemplated drawing a zigzag pattern of the conductive lines in a single stroke on the two-dimensional plane and to use the decrease in electrical resistance due to short circuiting when the liquid is in contact with the device as in the case of string or belt shape sensing device, and it is desirable to make resistance of the conductive lines higher by 
making the length of the conductive lines as long as possible so that detection of any decrease in resistance is easier when the liquid is in contact with the conductive lines.

Accordingly, the authors decided to use the conductive lines in a mesh pattern (shown in grey) in spiral $(7.2 \mathrm{~mm}$ square, mesh width $1.2 \mathrm{~mm}$ and insulation width $30 \mu \mathrm{m}$ ) in a single stroke, arranged in zigzag pattern (shown in yellow broken line) that are to be connected by the lead lines also formed by printing (shown in red) to make electrical resistance as high as possible as shown in Fig. 1. In the actual design, 1260 spirals (30 in vertical and 42 in horizontal direction) are arranged on A3 sized two-dimensional sheet in a single stroke pattern.

\section{Prototype and Check of Conductivity}

After the plate for the pattern of the conductive lines explained in the preceding section was prepared, printing of the conductive lines was made on 100 common PET sheets of A3 size as the two-dimensional transparent sheet to produce the prototype of the sensing device. (Fig. 2 shows a part of the device produced.) No defective sheet in which conductivity was lost was found when conductivity was checked for the respective sensing device.

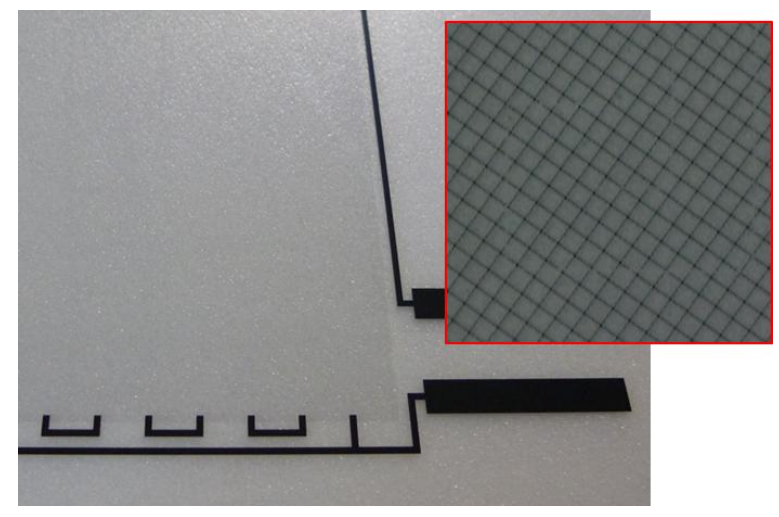

Fig. 2. A part of prototype and magnified image (60 times).

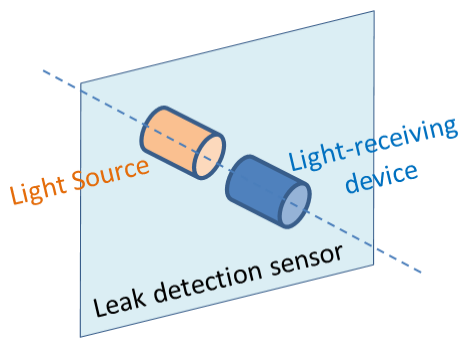

Fig. 3. Measurement method of transmittance rate.

\section{Performance Evaluation}

In this section, the performance evaluation of the sensing device produced is based on three criteria established by the authors, and evaluation of detecting capability of the liquid is also made in subsection 4.4 and after.

\section{A. Criterion 1 (Visible Transmittance)}

This subsection discusses the visible transmittance of the device. Visible transmittance at randomly selected 10 points was measured by placing the sensing device between the light source and the photo detector of the measuring equipment of visible transmittance of glass as shown in Fig. 3, and the measured values were averaged.

The result showed that the visible transmittance is $84.9 \%$ which is substantially higher than the criterion $(70 \%$ or above). This means that the prototype sensing device has adequate transparency that satisfies Criterion 1.

\section{B. Criterion 2 (Two-dimensional Sensing)}

This subsection discusses whether the prototype device can sense the liquid two-dimensionally. The device developed by the authors senses liquid using electrical behavior of the device due to presence of the liquid. So the experiments were conducted using sodium bicarbonate solution with a relatively high electrical conductivity and that is easily available.

After 10 sheets of the sensing device randomly selected (a through $\mathrm{j}$ ) were placed on the horizontal plane, $3 \mathrm{~mL}$ of sodium bicarbonate solution was dropped at the point randomly selected on the device where the conductive lines were printed and change in electrical resistance of the device was measured. The results indicate that electrical resistance of each device decreased as soon as the solution was dropped (see Fig. 4). This means that the prototype sensing device has the ability to detect the liquid present around randomly selected point on the surface to which the conductive lines are printed and satisfies Criterion 2.

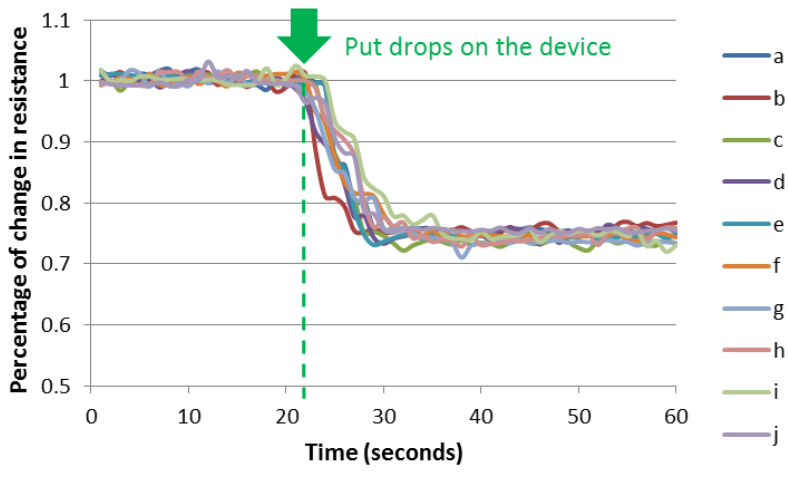

Fig. 4. Appearance of change in resistance.

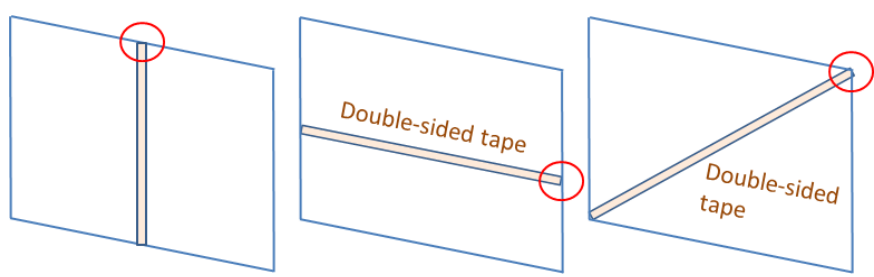

Fig. 5. Paste of double-sided tape and peel off point.

\section{Criterion 3 (Flexibility)}

This subsection discusses the prototype device with the required flexibility. The authors prepared four types of double-sided adhesive tapes with different adhesive strength (double-sided paper tape of Nichiban Co., Ltd., with width of $15 \mathrm{~mm}$ and adhesive strength weak, medium, strong, and super-strong). The total of 12 test pieces of the sensing device were prepared by three types of tape application for the respective types of double-sided tape as shown in Fig. 5. The double-sided tapes were applied to the other side of the test piece on which the conductive lines were printed.

Next, the backing paper of the tape was removed and each test piece was attached to the smooth surface (back of the 
steel office cabinet), and holding the edge of the device (a point in a circle in Fig. 5) the sheet was peeled off in the direction of 90 degrees. Rate of peeling-off the tape was 300 $\mathrm{mm} / \mathrm{min}$, which is based on JIS Z0237 for testing of the adhesive tape.

Table IV shows comparative results of average electrical resistance measured before and after each device was peeled off from the surface according to the method described above. As variation of resistance of the devices before they were peeled off was $\pm 3 \%$, the breakage of the conductive lines was unlikely. This means that the prototype sensing device has adequate flexibility that satisfies Criterion 3.

\section{TABLE IV: MEASUREMENT RESULTS OF RESISTANCE}

\begin{tabular}{|c|c|c|c|c|}
\hline No. & \multicolumn{2}{|c|}{$\begin{array}{c}\text { Type and Application } \\
\text { Method of Double-sided } \\
\text { Tape }\end{array}$} & \multirow{2}{*}{$\begin{array}{c}\begin{array}{c}\text { Resistance } \\
\text { before Peeling - } \\
\text { off }(k \Omega)\end{array} \\
22.36\end{array}$} & \multirow{2}{*}{$\begin{array}{c}\begin{array}{c}\text { Resistance after } \\
\text { Peeling - off } \\
(k \Omega)\end{array} \\
22.37\end{array}$} \\
\hline 1 & \multirow{3}{*}{ Weak } & Vertical & & \\
\hline 2 & & Horizontal & 21.91 & 21.92 \\
\hline 3 & & Oblique & 22.30 & 22.31 \\
\hline 4 & \multirow{3}{*}{ Moderate } & Vertical & 21.93 & 21.95 \\
\hline 5 & & Horizontal & 21.82 & 21.83 \\
\hline 6 & & Oblique & 22.82 & 22.22 \\
\hline 7 & \multirow{3}{*}{ Strong } & Vertical & 21.23 & 21.27 \\
\hline 8 & & Horizontal & 21.42 & 21.43 \\
\hline 9 & & Oblique & 21.57 & 21.72 \\
\hline 10 & \multirow{3}{*}{$\begin{array}{l}\text { Super- } \\
\text { strong }\end{array}$} & Vertical & 21.00 & 21.01 \\
\hline 11 & & Horizontal & 21.35 & 21.38 \\
\hline 12 & & Oblique & 21.50 & 21.52 \\
\hline
\end{tabular}

\section{Detection Ability 1 (Type of Liquid)}

This subsection discusses to what type of liquid this device is suitable for detection.

\section{1) Common liquids}

The experiments were conducted for five types of liquids (distilled water, tap water, ethanol, vinegar, and sodium bicarbonate solution) that are easily available (Table V shows properties of these liquids).

Five sheets of sensing devices were randomly selected and placed on the horizontal plane, and changes in electrical resistance were observed by dropping $3 \mathrm{~mL}$ (15 degrees $\mathrm{C}$ ) of each liquid on to the center of the respective device (the liquid dropped on the device formed a circle of about $4 \mathrm{~cm}$ in diameter). The results indicated that resistance changed only when tap water, vinegar, and sodium bicarbonate solution were dropped, and the degree of change for tap water was less than for vinegar and sodium bicarbonate solution (see Fig. 6).

TABLE V: MEASUREMENT Results of Resistance (15 DegreEs C)

\begin{tabular}{ccc}
\hline \hline Description & $\mathrm{pH}$ & $\begin{array}{c}\text { Conductivity } \\
(\mu S / \mathrm{cm})\end{array}$ \\
\hline Distilled water & 7.9 & 8 \\
\hline Ethanol & 5.7 & 10 \\
\hline Tap water & 7.7 & 275 \\
\hline Vinegar & 2.7 & 1,410 \\
\hline Sodium bicarbonate solution & 8.1 & 4,430 \\
\hline \hline
\end{tabular}

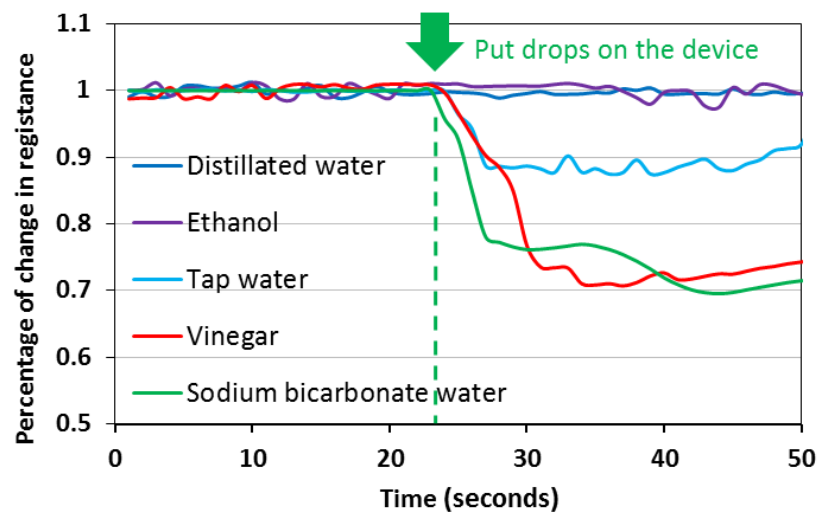

Fig. 6. Appearance of change in resistance.

The results indicated that a liquid with higher electrical conductivity could be more sensitively detected by the prototype sensing device.

\section{2) Liquids with strong acidity or alkalinity}

The experiments were conducted for hydrochloric acid and sulfuric acid that are strong acids and for sodium hydroxide solution that is strong alkaline solution (Table VI shows properties of these liquids). As the apparatus used to measure $\mathrm{pH}$ and electrical conductivity in above (1) was not compatible with strong acidity and alkalinity, $\mathrm{pH}$ was based on visual determination of the $\mathrm{pH}$ indicator paper and conductivity was based on the values from [19].

TABLE VI: CHARACTERISTICS OF EACH LIQUID (25 DEGREES C)

\begin{tabular}{ccc}
\hline \hline Description & $\mathrm{pH}$ & $\begin{array}{c}\text { Conductivity } \\
(\mu S / \mathrm{cm})\end{array}$ \\
\hline $\begin{array}{c}15 \% \text { hydrochloric acid } \\
15 \% \text { sulfuric acid }\end{array}$ & 0 & 820 \\
\hline $\begin{array}{c}15 \% \text { sodium hydrochloride } \\
\text { solution }\end{array}$ & 0 & 595 \\
\hline \hline
\end{tabular}

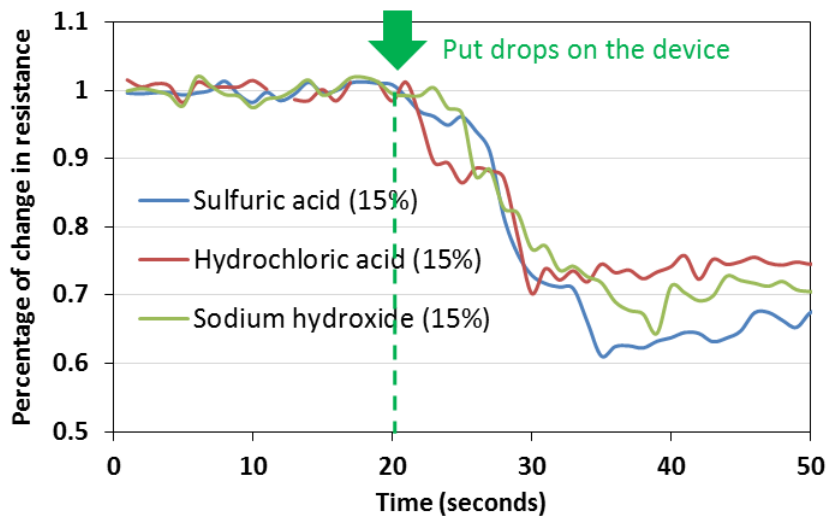

Fig. 7. Appearance of change in resistance.

Three sheets of sensing devices were randomly selected and placed on the horizontal plane, and changes in electrical resistance were observed by dropping $3 \mathrm{~mL}$ ( 15 degrees $\mathrm{C}$ ) of each liquid on to the center of the respective device (the liquid dropped on the device formed a circle of about $4 \mathrm{~cm}$ in diameter). Resistance decreased in the all cases (see Fig. 7). The results indicated that a liquid with strong acidity and alkalinity with higher electrical conductivity could be 
detected by the prototype sensing device.

\section{E. Detection Ability 2 (Liquid Volume / Liquid Particle Size)}

This subsection discusses about detection sensitivity of a liquid by the device.

\section{1) Liquid volume}

The similar experiments were conducted using the liquids used in 4.4 (1) (tap water, vinegar, and sodium bicarbonate solution) with reduced volume from $3 \mathrm{~mL}$ to $1 \mathrm{~mL}$. Three sheets of sensing devices were randomly selected and placed on the horizontal plane, and changes in electrical resistance were observed by dropping $1 \mathrm{~mL}$ (15 degrees $\mathrm{C}$ ) of each liquid on to the center of the respective device (the liquid dropped on the device formed a circle of about $2.5 \mathrm{~cm}$ in diameter). Although electrical resistance decreased when the liquid was dropped, the magnitude of the decrease was less than the results in 4.4 (1) (see Fig. 8). The results indicate that a liquid in larger volume could be more sensitively detected by the prototype sensing device.

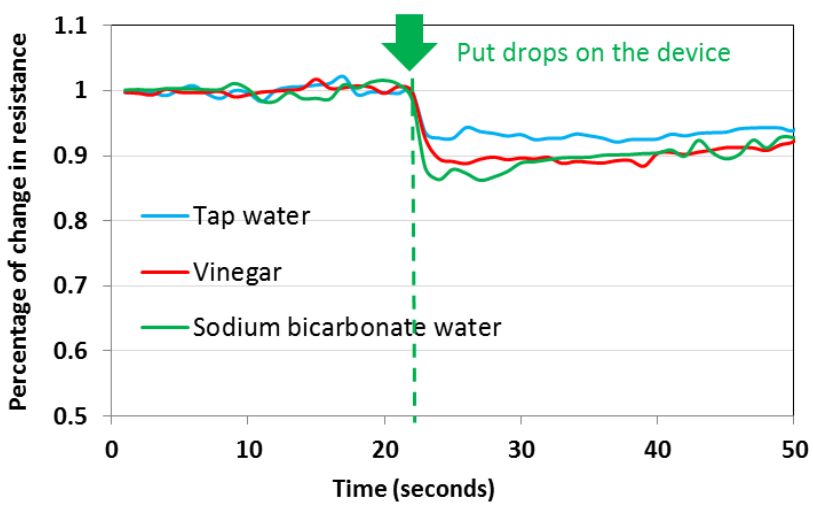

Fig. 8. Appearance of change in resistance.

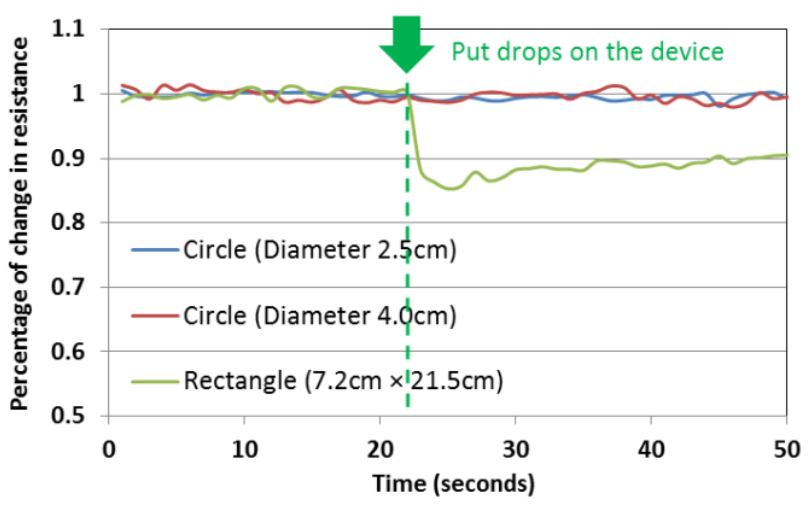

Fig. 9. Appearance of change in resistance.

\section{2) Liquid particle size}

The experiments were conducted to observe change in electrical resistance when tap water was sprayed over certain area of the sensing device. In the experiment, three sheets of sensing devices were randomly selected and placed on the horizontal place, and each device was covered using three masking sheets with the center of each sheet cut out in certain shape. The shapes of the cutout were a circle (diameter of 2.5 $\mathrm{cm}$ ), a circle (diameter of $4.0 \mathrm{~cm}$ ), and a rectangle $(7.2 \mathrm{~cm} \times$ $21.5 \mathrm{~cm}$ : an area equal to one closed circuit formed by the conductive lines), and each masking sheet was used to cover respective sensing device. Then change in electrical resistance was measured with tap water (15 degrees C) sprayed over the masking sheet uniformly. The resistance did not change when the cutout shape was a circle but resistance changed significantly when the shape was a rectangle (see Fig. 9).

The results indicated that a liquid in small particle size could be detected by the prototype sensing device when sensing area is large.

\section{DISCUSSIONS}

\section{A. Type, Volume, and Particle Size of Liquid for Sensing}

As shown by the results in Subsection 4.4 a liquid with higher electrical conductivity could be more sensitively detected by the prototype sensing device. It indicates that the sensing device is not suitable for detection of refined petroleum oil, cooking oil, deionized water, etc., that have low electrical conductivity.

As shown by the results in Subsection 4.5 the prototype sensing device can detect the liquid more sensitively with an increase of the liquid volume, and when the liquid particle size is small, it can detect the liquid more sensitively with increased area of exposure to the liquid. It indicates that it is difficult to satisfy the need to detect leakage in small volume or small volume leakage in a mist.

\section{B. Optimum Installation}

As shown by the results in Subsections 4.4 and 4.5 , the prototype sensing device can detect the liquid more sensitively with increase of the area of exposure to the liquid. Accordingly, the sensing device will be most appropriately installed by applying it on the tank or piping surface using a pressure sensitive adhesive etc. with the surface on which the conductive lines are printed facing to the tank or piping. The liquid will penetrate into a narrow clearance by capillary action when the sensing device is installed in this way regardless of orientation of gravity, which makes small volume of the liquid expand in wide area on the sensing device.

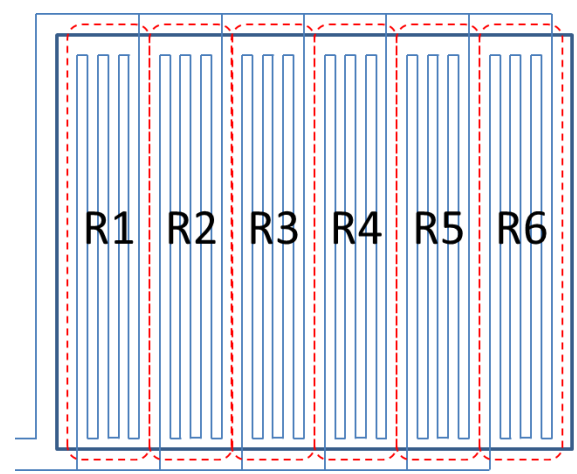

Fig. 10. Close circuits depicted by conductive lines.

\section{Identification of Leakage Point}

It is preferable that the sensing device developed by the authors can identify the point on the two-dimensional plane where leakage is detected. It makes repair of the leakage position more rapid, and it is applied to the string or belt shape sensing device to allow identification of an 
approximate point where the liquid is detected.

To allow such identification, the authors arrange multiple closed circuits of the conductive lines on the sheet and installed a load short circuit detection circuit to each closed circuit as shown in Fig. 10 that make identification of the point on the two-dimensional plane where the liquid is detected. By installing such short circuit detection circuit, protection from overcurrent caused by the short circuit becomes available, which will enhance safety.

\section{Durability and Weather Resistance}

Conductive lines printed on the PET sheet are consisting of the conductive silver powder and the conductive coating material. Although it is not clear to what extent the conductive lines are durable because composition of the conductive coating and results of the accelerated test or the service life prediction are not disclosed by the contractor who made the prototype, the sensing device will be used for extended periods of time, so far as the conductive coating material that attaches conductive silver powder on to the PET sheet has excellent durability and weather resistance as expected [20]. The authors intend to continue monitoring the results of accelerated test and service-life estimation for the coating material.

\section{E. Production Cost}

Consignment fees to produce prototype sensing device were about 5,000 USD. Because the breakdown of the costs was not disclosed, the cost for one sheet of sensor was about 50 USD by simple calculation, however, considering that about 200 USD is the prevailing cost for 100 PET sheets of that size and about 20 USD is the prevailing cost for $1 \mathrm{~kg}$ of conductive silver powder, it is reasonable to consider that majority of the costs was for the platemaking process (tracing, pattern making, and proofing). Generally speaking, cost for the above processes made by skilled manpower is relatively large, but once platemaking is complete, production (printing) in large quantity is possible using a machine and the cost for one sheet will decrease significantly.

\section{CONCLUSIONS}

The authors developed the transparent liquid leakage sensing device considering that there are potential needs for such device. The principle of detection is the same as that of the existing sensing device but visible transmittance is improved by making width of the conductive lines printed on the transparent sheet thinner and yield of the quality products is increased by mesh type arrangement of the conductive lines.

The prototype of the sensing device designed was produced, and the performance evaluation of the prototype was conducted using different types of liquids to verify effectiveness and usefulness of the device. The results indicate that visible transmittance of the device is as high as $84.9 \%$, and no defective product that lacks conductivity of the conductive lines was found. It is also found that the liquid with high electrical conductivity can be detected and detection is easier when the area of the sensing devise exposed to the liquid is large. As printing process is used to produce the conductive lines, this sensing device is suitable for mass production which allows availability at low cost.

The authors will increase transparency of the device and study the arrangement of the conductive lines to improve sensitivity in detection.

\section{REFERENCES}

[1] Panasonic Industrial Automation Sales, Leak sensor EX-F70/F60 series. [Online]. Available: http://www.bayat.com/storage/product-literature/panasonic/sensors/le ak-detection/ex-f60_70-catalog.pdf

[2] Toyoko kagaku Co., Ltd., Liquid leakage sensor operation manual for RS-3000FA/FAP. [Online]. Available: http://www.toyokokagaku.co.jp/product/pdf/RS-3000_eng-manual.pd f

[3] Tatsuta Electric Wire \& Cables Co., Ltd., Water leakage detection system (AD-PA). [Online]. Available: http://www.tatsuta.com/products/sensor/pdf/WLDS_products\%20cata log.pdf

[4] Junkosha Inc., Leaklearn, (FDF-L-10 / FDF-H-10 / FDF-L-150 / FDF / L-150W / FDF-L-200 / FDF-L-10N / FDF-H-10N / BE-6). [Online]. Available: http://www.junkosha.co.jp/item/pdf/fr002_3.pdf

[5] OMRON Corporation, Liquid leakage sensing band (F03-16PE / F03 / 16PS-F). [Online]. Available: http://www.fa.omron.com.cn/data_pdf/cat/f03-16sf_16sfc_dsheet_gw f072-e1-01a.pdf?id=1896

[6] COPAL Electronics, Liquid leak sensor WL10. [Online]. Available: http://www.inter-elink.com/Pic/File/WL10.PDF

[7] Technical \& Try Co., Ltd., Leakage sensor (LUP, KP, EFP-T, and TFP-F series). [Online]. Available: http://www.techtry.co.jp/leakage_en/

[8] Junkosha Inc, Leaklearn (DGW012 / DGW040 / DGW130A and DGD010 / DGD030A). [Online]. Available: http://www.junkosha.co.jp/item/pdf/fr002_3.pdf (Japanese text)

[9] Tatsuta Electric Wire \& Cables Co., Ltd., Water leakage detection system (AD-S / AD-RS / AD-HS / AD-FH / FR-AD / AD-LS) [Online]. Available: http://www.tatsuta.com/products/sensor/pdf/WLDS_products\%20cata log.pdf

[10] OMRON Corporation, Liquid leakage sensing band (F03-16F / F03-16SFC / F03-16PE / F03-16PT / F03-15 and F03-16UP-C). [Online]. Available: http://www.ia.omron.com/products/category/sensors/liquid-leakage-se nsors/liquid-leakage-sensors/index.html

[11] Junkosha Inc., Leaklearn (SB-10). [Online]. Available: http://sz.tipsun.com/junkosha/item/pdf/fr002_1.pdf (Japanese text)

[12] Tatsuta Electric Wire \& Cables Co., Ltd., Water leakage detection system (Leakage detection sheet). [Online]. p. 6. Available: http://www.tatsuta.co.jp/company/pdf/corporate_web2014.pdf

[13] 3M, Privacy and Screen Protectors. [Online]. Available: http://solutions.3m.com/wps/portal/3M/en_US/3MScreens_NA/Prote ctors/

[14] Ministry of Land, Infrastructure, Transport and Tourism. [Online]. Available:

http://www.mlit.go.jp/jidosha/kijyun/saimokukokuji/saikoku_195_00. pdf

[15] Tatsuta Electric Wire \& Cables Co., Ltd., Water leakage detection system technical document. [Online]. p. 5. Available: http://www.tse-sys.com/water/pdf/date_2011.pdf (Japanese text)

[16] 3M, FAQ. [Online]. Available: http://www.mmm.co.jp/tape-adh/faq/

[17] Nikkei Technology, DNP Produces Transparent Conductive Film by Printing Method, Looks to Replace ITO. [Online]. Available: http://techon.nikkeibp.co.jp/english/NEWS_EN/20090428/169479/

[18] Hitachi Chemical Co., Ltd., Establishing Mass Production System for Transparent Conductive Transfer Film Used in Touch Panels. [Online]. Available:

http://www.hitachi-chem.co.jp/english/information/2013/n_130129.ht $\mathrm{ml}$

[19] T\&C Technical, Technical Document. [Online]. p. 9. Available: http://www.incom.co.jp/company/cid_0007550/catalogue/node_1411 53/

[20] K. Sasaki, "A study of device joint reliability and conductive adhesive paste jisso for humidity acceleration test methods," in Proc. $21^{s t} R C J$ Reliability Symposium, no. 21S-06, 2011, pp. 197-204. 


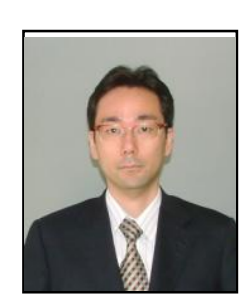

Masaki Fujikawa was born on 6 February 1974 in Tokushima Prefecture, Japan. He received his master's degree in information engineering in 1998 from Tokushima University, Tokushima Prefecture, Japan. In 2004, he received his Ph.D. in information engineering from Chuo University, Tokyo, Japan.

He joined the ALSOK, Tokyo Japan in 1998. He is a chief researcher of the company, and doing research on a variety of security and safety systems in order to

build a safer society.

Dr. Fujikawa is a member of IEEE, IPSJ and the steering committee of the IPSJ computer security group. Dr. Fujikawa received the specially selected paper award of the Information Processing Society of Japan in 2014.

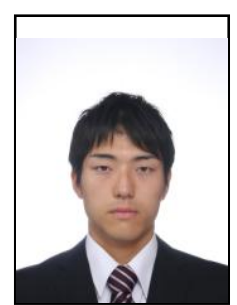

Kenta Miyazaki graduated from Nagaoka University of Technology in 2014. Currently, he is a student of master's degree program at the Department of Nuclear System Safety Engineering, Nagaoka University of Technology. In his research, he is studying about the power plant of the nuclear electric propulsion system for human space exploration by using numerical simulation. 